\title{
Author Correction: Reproductive hazards of space travel in women and men
}

\section{Birendra Mishra and Ulrike Luderer(D)}

Nature Reviews Endocrinology (2019) https://doi.org/10.1038/s41574-019-0267-6 Published online 14 October 2019.

The acknowledgements section was missing from the originally published article. The section should have read 'The authors acknowledge funding support from National Space Biomedical Research Institute (NSBRI) (B.M.), U.S. Department of Health \& Human Services, NIH National Institute of Environmental Health Sciences (NIEHS, National Institutes of Health; grant number R01ES020454) (U.L.) and National Aeronautics and Space Administration (NASA; grant number NNX14AC50G) (U.L.).' This has been corrected in the HTML and PDF versions of the manuscript.

https://doi.org/10.1038/s41574-019-0287-2 I Published online 30 October 2019 